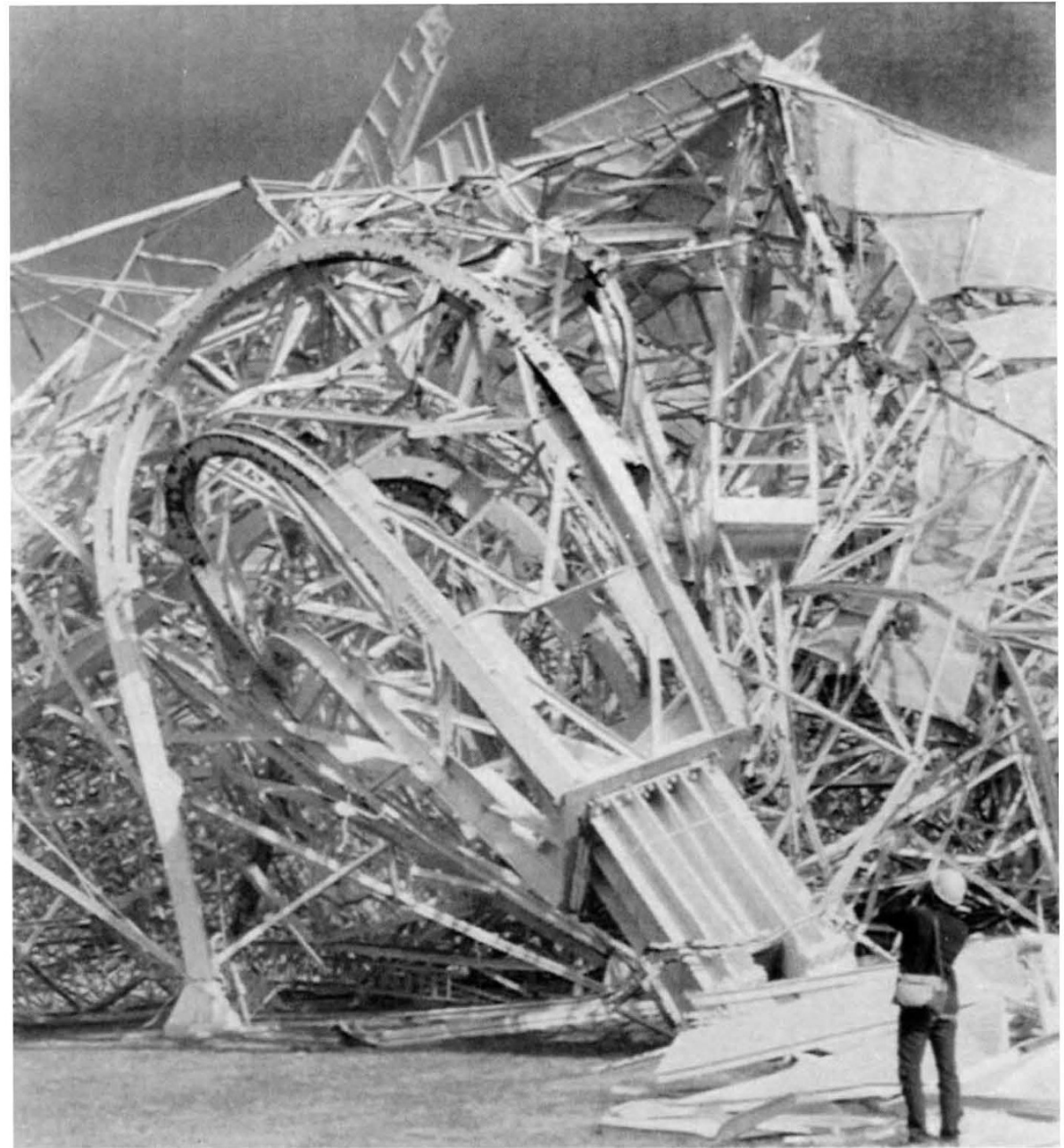

A worker at the National Radio Observatory photographs the debris.

\section{Expansion squeezed}

Berkeley

BUDGET limitations passed by California voters may prevent the University of California (UC) from expanding as it struggles to keep up with the state's growing population.

To maintain its policy of accepting the top 12.5 per cent of the state's high-school graduates, the UC system will need to increase its total enrolment from its present size of 154,000 graduate and undergraduate students to about 217,000 by the year 2005 . UC officials say the extra students cannot be accommodated on the existing nine campuses without compromising academic quality. UC president David P. Gardner has recommended the expansion of several of the existing campuses, in addition to building three new campuses, at a cost of $\$ 300$ million each, to open in 1998, 1999 and 2000.

Gardner's proposal may be in vain, however, because of voter-approved spending limitations imposed on the state. The 1979 'Gann limit', named for its sponsor, self-styled tax-revolt leader Paul Gann, puts a cap on state spending. An initiative passed by voters in November worsens the financial situation for UC, by assuring public primary and secondary schools and community colleges of a fixed percentage of each year's state budget, while giving UC no comparable assurance.

UC has made it clear that it will limit its enrolment rather than compromise academic quality, and if the state wants the university to continue to meet the needs of a growing population, the legislature must take action to reverse the voter-approved initiatives and remove the financial squeeze

Marcia Barinaga

\section{Celltech maturation}

mains a mystery. The radiotelescope, which is one of the world's largest and has been in use for 26 years, came crashing down last Tuesday night, bringing dozens of research projects to a halt.

According to Paul A. Vanden Bout, director of the National Radio Astronomy Observatory facility, there was "no wind, rain or snow" and the telescope had been working perfectly until the accident.

It is not even possible to tell whether the initial fault developed in the axle on which the dish is mounted or the two pylons holding the axle aloft, but all that is left is a heap of twisted metal. Nobody was hurt in the collapse, although the telescope operator in the control room was "shaken" and had considerable difficulty in convincing operators at Green Bank's other facility, a 140foot-diameter radiotelescope, that the accident really had happened.

An internal inquiry team has begun an investigation, said Vanden Bout, but it is under instructions "not to disturb the remains in any way" until an external team being hastily assembled by the National Science Foundation (NSF) arrives. Vanden Bout dismissed as "crazy" rumours that the 300-foot dish had been improperly designed.

The big dish was used for large-area sky searches and had played a key role in clarifying the origin of pulsars through the discovery of a pulsar at the heart of the Crab Nebula. At the time of collapse, the telescope was being used for a $6-\mathrm{cm}$ radio sky catalogue. A first pass had been completed and a second pass, looking for sources that had changed, was three-quarters complete. Almost all the data will still be usable.

Telescopes at Arecibo, Puerto Rico, and Effelsberg, West Germany, provide some of the same northern sky coverage as the Green Bank telescope but neither matches its capacity exactly.

Rebuilding would be very expensive. Pat Bautz, NSF's director of the division of astronomical sciences, says the telescope cost $\$ 850,000$ in 1962 . But astronomy is now very short of funds. Her first concern is to find out what went wrong.

Attempts are being made to reach NSF director Erich Bloch who is on his way to the Antarctic.
Alun Anderson

\section{London}

AN end to the special relationship between the UK Medical Research Council (MRC) and the leading UK biotechnology company, Celltech Ltd, has been announced. The eight-year-old company owes much of its initial success to its exclusive first rights to MRC discoveries in biotechnology. Five years ago, the company's privileges were reduced by MRC, and now all that remains is an agreement that the council will keep the company informed of technology developments in exchange for information of the company's interests and plans.

Celltech, meanwhile, has notched up its second profitable year, but only just. With turnover increasing from $£ 11.5$ million to $£ 16.6$ million in 1987 , profits fell by nearly half to an unimpressive $£ 125,000$, and only because a considerable increase in interest income offset extra costs involved in developing potential pharmaceutical products.

Peter Newmark 